\title{
ATUAÇÃO DOS ENFERMEIROS NA HUMANIZAÇÃO E NO ACOLHIMENTO DA FAMÍLIA E DOS PACIENTES EM UNIDADE DE TERAPIA INTENSIVA
}

\section{REVISÃO INTEGRATIVA}

SANTOS, Tereza Fernanda Pereira ${ }^{1}$

JUNIOR, Adival José Reinert ${ }^{2}$

SANTOS, Tereza Fernanda Pereira. JUNIOR, Adival José Reinert. Atuação dos enfermeiros na humanização e no acolhimento da família e dos pacientes em unidade de terapia intensiva. Revista Científica Multidisciplinar Núcleo do Conhecimento. Ano 04, Ed. 10, Vol. 01, pp. 25- 37. Setembro de 2019. ISSN: 24480959, Link de acesso: https://www.nucleodoconhecimento.com.br/saude/atuacaodos-enfermeiros

\section{RESUMO}

A Unidade de Terapia Intensiva (UTI) é um ambiente onde se encontram pacientes em estado grave que precisam de uma assistência de Enfermagem qualificada e especializada, com monitoramento tecnológico 24 horas por dia. O enfermeiro na UTI é responsável por acompanhar e cuidar constantemente do paciente, e tem o compromisso dentre outros, de nutrir a estabilização do paciente e o bom andamento da unidade, tanto nos eventos de emergência quanto no apoio à vida. O estudo tem caráter exploratório, de natureza qualitativa sem sujeitos e amostras, baseando-se na

\footnotetext{
${ }^{1}$ Pós-Graduada em Saúde da Família; Gestão em Saúde Pública; Enfermagem em Urgência e Emergência e Terapia Intensiva; Graduada pela Faculdade Estácio de Sergipe.

2 Especialização em Teoria Psicanalítica; Especialização em Orientação, Supervisão e Gestão Escolar Democrática; Especialização em Docência do Ensino Fundamental, Médio e Superior; Graduação em Matemática.
} 
literatura por meio de livros, teses e artigos científicos para responder seus objetivos. O objetivo geral da presente pesquisa é entender a importância da humanização no acolhimento da família e dos pacientes por parte dos enfermeiros. Já como objetivos específicos busca: Apresentar a função o enfermeiro na UTI; descrever como funciona a humanização em Enfermagem na UTI e analisar a sistematização da Assistência de Enfermagem (SAE). Concluiu-se a grande relevância da humanização no acolhimento dos familiares e pacientes internados em Unidades de Terapia Intensiva, e que para que toda equipe possa atingir os objetivos de humanização é necessário não somente acolher os pacientes, como também sua família. Nota-se, portanto, que o estudo em questão pode servir de base para confecção de outros estudos, bem como servir de conhecimento para os enfermeiros que desejam atuar em Unidades de terapia intensiva.

Palavras-Chave: Enfermagem, Unidade de Terapia Intensiva.

\section{INTRODUÇÃO}

A unidade de terapia intensiva é um lugar onde os pacientes se deparam em um estado crítico e que precisam de uma assistência de enfermagem qualificada e especializada, com monitoração 24 horas. Alterações psicológicas e sociais podem ocorrer ao paciente e sua família quando estão hospitalizados em uma UTI. Sendo assim, o cuidado holístico precisa abranger todo o acolhimento com a família, recuperando o conceito de bem-estar biossocial psicoespiritual, o que amplia o campo de desempenho do profissional de enfermagem intensivista.

Os enfermeiros precisam estar dispostos para obrar junto aos pacientes e familiares no sentido de diminuir os efeitos e transtornos resultantes da hospitalização na UTI. É preciso levar em consideração que a família é afetada de várias formas: como alteração do papel social, incertezas das condições futuras do paciente, perda do controle das emoções e dentre outros obstáculos vivenciados.

Quando a família compreende a doença do paciente, o motivo dele estar na Unidade de Terapia Intensiva, à relevância do cuidado para a recuperação da doença e os 
agravos que podem acontecer, a família pode responder de maneira positiva a todas as mudanças geradas por conta da internação, reduzindo os efeitos da doença e passando a ajudar a pessoa em todas as mudanças que acontecem (PENA e DIOGO, 2005).

Justifica-se a pesquisa como de grande importância para o profissional de enfermagem, alunos e leitores em geral que buscam conhecer a respeito do trabalho desenvolvido pelos profissionais de enfermagem nas unidades de terapia intensiva. É uma pesquisa que busca criar conteúdo para embasar novos estudos a respeito do tema, demostrando a grande importância dos enfermeiros junto as famílias e pacientes nas UTIs.

O presente estudo tem caráter exploratório, de natureza qualitativa sem sujeitos e amostras, baseando-se na literatura por meio de livros, teses e artigos científicos para responder seus objetivos.

O objetivo geral da presente pesquisa é entender a importância da humanização e no acolhimento da família e dos pacientes por parte dos enfermeiros. Já como objetivos específicos busca: Apresentar a função o enfermeiro na UTI; Descrever como funciona a humanização em Enfermagem na UTI e analisar a sistematização da Assistência de Enfermagem (SAE).

\section{ATUAÇÃO DOS ENFERMEIROS NA HUMANIZAÇÃO E NO ACOLHIMENTO DA FAMÍLIA E DOS PACIENTES NA UTI}

- Unidade De Terapia Intensiva - UTI

A UTI é uma estrutura hospitalar complexa atribuída de sistema de monitorização contínua que acolhe usuários de forma potencial graves ou com descompensação de um ou mais sistemas orgânicos, e que com o apoio e tratamento intensivos possam se recuperar (CREMESP, 1995).

A conceituação de UTI foi fundamentada na necessidade de fornecer um suporte contínuo de complexidade alta para pacientes em estado grave, instáveis ou com 
doenças agudas que irão depender de uma assistência avançada para poder sobreviver. Na unidade de terapia intensiva as visitas se limitam a área reservada para o paciente o qual fica em vigilância constante durante 24 horas.

A UTI faz parte o setor de complexidade alta do hospital, e se integra a outros graus de atenção à saúde, com serviços de alta densidade tecnológica, necessidade superior de suporte especializado, exames de laboratório e de imagem, dentro outros (NOGUEIRA et al, 2012).

De acordo com Grenvik e Pinsky (2009) falando de história, é preciso lembrar da enfermeira britânica Florence Nightingale que participou da guerra da Criméia, e a qual idealizou o conceito de atendimento contínuo. Na guerra, ela separou os feridos mais graves em uma enfermaria próxima e criou uma estratégia de rápido atendimento. No começo do século $\mathrm{XX}$, as primeiras enfermarias de atendimento começaram a surgir nos Estados Unidos e eram destinadas a acompanhar pacientes em pós-operatório de cirurgias mais complexas, a exemplo das neurocirurgias. Essas primeiras enfermarias de atendimento continuado demonstrava um número superior de sobrevida e uma melhor evolução.

O avanço dos cuidados aos pacientes graves ocorreu por conta a epidemia de poliomielite na década de 50 do século passado. Nesse momento equipamentos para suporte respiratório mais eficientes começaram a surgir e serem usados, e com isso, as taxas de mortalidade diminuíram, e isso fez com que houvesse a disseminação e instalações de enfermaria para cuidados respiratórios especiais na Europa e América do Norte (GRENVIK e PINSKY,2009).

Os cuidados intensivos no Brasil, teve seu início em São Paulo, na faculdade de medicina no Instituto de Ortopedia, em 1955, com a utilização dos primeiros respiradores artificiais para cuidar dos casos mais complexos de poliomielite que afligia o país. Em 1962, o médico austríaco Peter Saffar, estabeleceu a primeira unidade intensiva cirurgia na universidade de Pittsburgh e iniciou o conceito de monitoração 24 horas e criou a primeira disciplina médica de apoio crítico. 
Ainda na mesma época inaugurou-se UTIs para acompanhar todo pós-operatório de pacientes sujeitos a cirurgia cardíaca, logo após foi embutido o conceito de internação de usuários com problemas cardíacos clínicos em terapia intensiva (GRENVIK e PINSKY,2009).

À medida que os anos foram passando, as Unidades de Terapias Intensivas foram se especializando de forma que, nos dias atuais é comum em centros grandes existir a separação quanto aos casos, se clínico, pediátrico e cirúrgico. Ao mesmo tempo, ocorreu uma especialização de profissionais para agirem nessa área, com formação de médicos e enfermeiros dedicados de forma exclusiva à medicina intensiva que foram seguidos pelo desenvolvimento de equipamentos de alta tecnologia de suporte à vida e de materiais fabricados, especialmente, para esse fim o que acontece até os dias de hoje (FERNANDES e COSTA FILHO, 2010).

- Funções do profissional de enfermagem na UTI

Conforme o decreto-Lei oㅜ 94.406 de 8 de junho de 1987, regulamentada Lei ํㅜ 7.498, de 25 de junho de 1986, que apresenta a respeito do exercício legal da Enfermagem. Segundo esta lei, o profissional desempenha todas as atividades de Enfermagem, onde lhe cabe privativamente, dentre outras atividades: planejar, organizar, coordenar, executar e avaliar os serviços da assistência de enfermagem (FREITAS e OQUISSO, 2007).

Para o profissional de enfermagem assistencial da Unidade intensiva é possível

analisar os familiares, seus medos e expressões, questionamentos e suas formas de como se aproximam e se comportam perante a equipe. O enfermeiro na UTI responsabiliza-se por seguir e cuidar constantemente o paciente, tem o compromisso, de nutrir a estabilização do paciente e o bom andamento da unidade, tanto nos eventos de emergência quanto no apoio à vida.

Um dos grandes diferenciais no mercado competitivo são os indivíduos, e sendo assim, preparar adequadamente os profissionais constituem um importante meio para a qualidade e o cuidado prestado a unidade intensiva. A conexão de conhecimento e 
das habilidades de um profissional de enfermagem para cuidar de um paciente em particular, precisa ser claro não só por meio de observações escritas bem como, por meio dos cuidados clínicos proporcionados e da habilidade apresentada na alteração das prioridades preconizadas pelo que o paciente precisa (JERONIMO; CHEREGATTI, 2011).

Para Silva (2000) as atividades na unidade intensiva, tem quatro funções primordiais:

- Controle;

- Planejamento;

- Direção;

- Organização;

O profissional de enfermagem da unidade intensiva tem a expectativa que essas funções possam suprir todas as necessidades dos pacientes, pois o objetivo final é gerar cuidado e segurança. Além disso, o autor apresenta que o enfermeiro tem papel primordial na UTI, pois não só observa as atividades do cotidiano, como faz provisões de materiais e medicamentos, acolhe familiares e se torna um modelo de humanização encantando assim, a participação dos familiares.

A sistematização da assistência de enfermagem (SAE) é um instrumento muito relevante para o profissional de enfermagem e a mesma é combinada pelo histórico, exames físicos, prescrições de enfermagem e diagnóstico.

A SAE é particular do enfermeiro e sua aplicação está antevista na Resolução do COFEN no 272/2002, que ordena sobre a SAE nas instituições de saúde do Brasil. O processo de enfermagem é um artifício sistemático e organizado de coordenação das atividades prescritas ao paciente em um plano abrangente de tratamento (JERONIMO e CHEREGATTI, 2011).

Segundo as exigências das unidades de terapia intensiva, os enfermeiros necessitam associar suas habilidades técnicas e intelectuais a prática do dia a dia. Isso constitui que eles precisam ter habilidades e competência que os façam desenvolver suas 
funções de maneira eficaz e eficiente, onde une os conhecimentos científicos aos técnicos, a tecnologia, individualização o cuidado e a humanização (SILVA, 2003).

O papel do profissional de enfermagem na UTI incide em alcançar a história do paciente, realizar exame físico, tratamento, aconselhando e instruir a manutenção da saúde, guiando os pacientes para uma continuidade do tratamento e medidas, necessitando cuidar do paciente nas diversas circunstâncias críticas dentro da UTI, de maneira conexa e contínua com todos os membros do grupo de saúde.

O enfermeiro necessita de um conhecimento desde administrar o resultado das drogas até como funciona e se adequa aparelhos, pois estes cuidados estão conectados em suas atividades rotineiras e precisam ser por ele coordenados, junto a um atendimento humanizado. Os enfermeiros da UTI passam grande parte do seu tempo dedicando-se a monitoração do estado dos pacientes, podendo identificar os diagnósticos do enfermeiro, conseguindo reconhecer sinais e sintomas antecipados de potenciais complicações.

Os planos de tratamento do profissional de medicina e enfermagem se diferenciam, o médico foca em tratar a doença, já o enfermeiro busca nortear os cuidados, analisar as respostas dos pacientes referente à sua doença e ao tratamento a ele proposto, pois o enfermeiro precisa ir de encontro com as precisões do paciente que está lutando para sobreviver (SOUSA; PADILHA, 2000).

Mesmo existindo muitos profissionais que operam na unidade de terapia intensiva, o profissional de enfermagem é o maior responsável por acompanhar constantemente a unidade, pois precisa ter o compromisso de nutrir e conservar o bom funcionamento; aferir, sistematizar e deliberar a respeito da utilização apropriada de recursos humanos, físicos, materiais e de informação no cuidado ao paciente de terapia intensiva.

Além de todas as responsabilidades já mencionadas, o enfermeiro tem papel extremamente importante em gerar o desenvolvimento do pensamento crítico, verificando os problemas e achar soluções asseverando sempre seu exercício dentro 
dos princípios éticos da profissão. Menciona Silva (2003) que o trabalho em UTI é difícil e intenso, e o enfermeiro tem que estar capacitado para desenvolver todas as atividades de grande complexidade, precisando estarem muito confiantes para conduzir todo atendimento do paciente. O profissional precisa ter conhecimento aprofundado e específico, além de ter habilidade para conseguir tomar decisões muito rápidas.

- Sistematização da Assistência de Enfermagem (SAE)

A (SAE) é o aparelho profissional de enfermagem, que direciona sua prática e pode aprovisionar autonomia profissional e consolidar a proposta de propiciar, nutrir ou compor o nível de saúde do usuário, como também registrar sua prática profissional, buscando à análise da qualidade da assistência apresentada, tendo uma abordagem holística, auxiliando e assegurando que as intervenções sejam formadas para o sujeito e não somente para a doença, agilizando análises e intervenções, gerando melhora de comunicação e acautelando falhas e omissões (MACHADO, 2010).

De acordo com Backes et al. (2005), a SAE retrata a construção eficaz de um espaço novo cultural regressado para um sistema de valores que implica a sobrelevação constante da incredulidade e do comodismo, da fragmentação e da burocracia, com a intenção de incitar a libertação da capacidade criadora e da subjetividade, aspirando uma nova compreensão da realidade, sendo assim, uma modificação no papel do enfermeiro.

A autonomia na profissão só será alcançada quando todos começarem a usar a metodologia científica, que é a Sistematização da Assistência de Enfermagem, em seus atos, sendo assim, quando estiver em prática do bom emprego sistemático do método de enfermagem (TANNURE e GONÇALVES, 2008).

Já de acordo com Moraes e Peniche (2003) a sistematização da assistência alude no uso de um método de trabalho, seja qual for o referencial teórico usado, e solicita do enfermeiro interesse em ver o paciente como indivíduo, usando para isto suas 
habilidades e conhecimentos, além de orientar e treinar a equipe de enfermagem para a implementação das atuações sistematizadas.

A basilar função da SAE é dirigir a prática, assim, o procedimento agregado precisa de simplicidade para provocar a prática e ser aplicada à realidade, onde adapta-se às necessidades de cada pessoa. Esse procedimento necessita admitir máxima afinidade do profissional de enfermagem com o paciente e os familiares, permitindo ainda assistência regulada em conhecimentos científicos (PICCOLI e MATOS, 2003).

Para que o profissional exerça de maneira distinta a sua função e possa colaborar com benfeitorias ao paciente, necessita oferecer uma assistência sistematizada, contornando suas atuações mais científicas possíveis (CUNHA, 2006).

Para Amante et al (2009) o processo de enfermagem na UTI se torna indispensável por conta da gravidade das situações de saúde dos pacientes que se encontram internados, determinando uma observação e exame físico apropriados, a precisão de ação acelerada, segura e ativa da equipe de ao longo tempo de duração desses pacientes no ambiente do hospital.

Os diagnósticos precisam ser apresentados e elencados em ordem de prioridades, com alicerce no grau de advertências ao nível de bem-estar do usuário, harmonizando, dessa forma um enfoco central para as etapas subsequentes.

Eles são muito benéficas para a concretização das atividades práticas e clínicas dos profissionais de enfermagem e ajudam para a implantar a fase seguinte do processo, uma vez que permite a assimilação dos problemas do indivíduo com vistas a reestabelecer e promover a saúde (TANNURE e GONÇALVES, 2008).

\section{- Procedimentos realizados em UTI}

As UTl's são locais que se destinam a prestar assistência especializada a pacientes em um estado crítico, onde recebem cuidados e que são desempenhados por uma equipe de grande qualificação, por intermédio de controle rígido dos padrões vitais e assistência continuada. Os eventos divergentes que podem acontecer em UTI 
requerem análise particular, considerando que o paciente grave apresenta propriedades que o tornam mais passível a falhas. Dessa forma, eles precisam ser examinados para conseguir identificar problemas estruturais (SILVA, 2003).

Quando um paciente adentra a UTI, o paciente tem como intenção seu tratamento, e para isso, espera por profissionais capacitados, bons recursos de tecnologia, materiais apropriados, conforto nas acomodações e um tratamento com muita qualidade (KNOBEL,2006).

Para Knobel (2006) todos os profissionais que se envolvem no acolhimento ou na internação de pacientes em uma UTI, precisam estar preocupados com a garantia e o bem-estar dos mesmos, pois a maneira com que é recebido ficará registrado e irá determinar a geração de conexão entre paciente e equipe e o paciente. A 'anamnese' é a entrevista inicial e pode ser o diferencial no processo de hospitalização, pois não somente o paciente como seus acompanhantes precisam ser bem acolhidos, e consequentemente no oferecimento da saúde (SILVA, 2003). É preciso que todas as informações passadas tanto a família quanto aos pacientes seja clara, pois é um fator extraordinário no tratamento (STEFANELLI, 1993).

Completando essa ideia, Silva (2003) apresenta que o registro de todos os procedimentos precisa ser correto para que a leitura da equipe seja. Conforme apresentado, a admissão de um paciente na UTI precisa seguir um protocolo para que seja feita uma maneira segura.

- Interação entre a familiares e os pacientes da UTI

$\mathrm{Na}$ UTI, apresenta Comassetto (2006) que a internação no hospital causa muito desequilíbrio emocional para todos os envolvidos, principalmente por estarem vivendo uma circunstância não planejada. Além disso, a UTI é um local que busca reduzir o sofrimento do paciente e da família no decorrer da permanência.

Quando existe a precisão de uma internação, há um nível alto de estresse, acarretando insegurança, por conta da visão errada que o paciente e sua família têm desta unidade, por ausência de conhecimento e do adequado amparo dispensado, 
pois integram esta unidade com uma circunstância de desespero e isolamento da família e amigos com a possível morte. Acredita-se na relevância de estimular a família no acompanhamento do tratamento, distinguindo os resultados positivos contraídos pelo paciente quando contido ao tratamento na UTI (MEZZOMO, 2001).

Outro ângulo extraordinário é a interação dos familiares com toda equipe, amparando e participando das decisões, procurando atenuar os momentos vividos, pondo um cuidado humanizado. Quanto antes for a relação existente entre família e enfermeiro, melhor será para o paciente (PAULI; BOUSSO, 2003). É de suma importância para o paciente e sua família entender que a UTI é uma fase importante para superar a doença, no entanto, é relevante reduzir a dor e gerar maior conforto, independente do prognóstico, pois esta é a atribuição de todos os profissionais da unidade.

É importante que seja permitido que os familiares e amigos possam ver todos os dias os pacientes, para que não e sinta apenas um paciente, mas que seja ajudado no desejo de atuar e se recuperar o quanto antes, pois a ajuda é de extrema relevância neste momento complexo, especialmente, porque seus familiares são tidos como sujeitos congregados ao tratamento, cooperando para que o paciente se sinta resguardado e amado e sendo incitado a lutar pela própria vida (COMASSETTO, 2006).

É de grande seriedade que exista uma influência mútua dos familiares com o paciente, pois a experiência de ambos é marcada especialmente por ações no dia a dia em favor do bem-estar de todos.

- Humanização, uma maneira de destacar o atendimento em uma unidade de terapia intensiva

A UTI vem a ser um dos campos que mais exacerbam a desesperança a angustia e medo que as famílias têm e pelo próprio enfermo. Por conta de todo o uso de técnicas e tecnologia, muitos profissionais em diversas ocasiões acabam por desumanizar a assistência. É de grande relevância mudar esse quadro, e fazer com que recupere o 
estado biopsicossocioespiritual dos pacientes, além de prestar atendimento de forma singular (OLIVEIRA et al, 2013).

Ainda de acordo com Oliveira et al (2013) apesar de toda tecnologia, e técnicas complexas, é preciso comprovar a eficácia dos estudos que apresentam que a atenção dedicada aos pacientes, além do diálogo são vertentes de humanização e assistência.

A política Nacional de Humanização $(\mathrm{PNH})$ propõe estratégias que possibilitem atenção integral aos pacientes, além de ampliar as condições de direito e de cidadania. A PNH apresenta em seu texto, a ideia a qual pode-se ter várias interpretações para cada situação e com cada pessoa por seu conceito subjetivo, dessa forma, a política nacional não determina um único conceito e sim uma compreensão a respeito do que é a humanização (COSTA, et al, 2009).

A humanização traz dignidade ao atendimento em meio da todas as precisões do hospital, dos pacientes e de toda equipe, sempre de maneira mais ética e humana, sendo assim, toda estrutura do hospital coloca-se a serviço dos usuários, levando a maior qualidade possível (COSTA et al, 2009). Porém, de acordo com Salicio e Gaiva (2006) é muito difícil manter todo o cuidado humanizado, mesmo quando os profissionais saibam o quanto a humanização é importante no processo completo de recuperação.

É necessário que seja dada um tratamento mais humano, apurando a necessidades, unindo toda a prática a tecnologia proporcionada e não fazendo com que os profissionais dependam dela, impedindo rotinas pré-definidas, sempre buscando novas linhas de atendimento e buscando sempre atender as necessidades dos pacientes.

\section{- Humanização em Enfermagem na UTI}

A humanização vem sendo aos poucos implantadas, e tem como intenção primordial gerar melhoras do serviço e do atendimento oferecido, precisando ser proporcionado por todos da equipe de saúde (BRASIL, 2002). 
De acordo com Oliveira (2001) a humanização é caracterizada como colocar mente e coração nas tarefas a serem desenvolvidas, entregando-se de forma sincera e leal ao outro, além de saber ouvir e ter paciência.

Já segundo Lima (2013) dar um atendimento humanizado não solicita apenas doar um tempo maior ao paciente, mas sim, oferecer uma assistência de maneira holística, entendendo que cada paciente é uma realidade nova.

Crê-se que apenas e possível humanizar o atendimento em uma Unidade de terapia Intensiva, perante nossa própria humanização, sendo assim, a equipe só pode prestar atendimento humanizado quando aprender a ser integro consigo mesmo (WALDOW, 2004).

Os profissionais enfermeiros quando adquirem formação, têm dado prioridade a especialização em procura de aperfeiçoar seu conhecimento, se tornando habilitados e capacitados, para cada vez mais proporcionar o melhor atendimento e por conseguinte cura e recuperação dos pacientes (MARTINS e NASCIMENTO, 2005).

Para atender a rotina do dia a dia complexo que abrange UTI, os enfermeiros acabam desenvolvendo uma assistência mecanizada e não humanizada. A humanização está ligada a quem está desenvolvendo-a, ou seja, envolve estado físico, mental e psicológico (FREITAS; OGUISSO, 2007).

A prática de um cuidado desumanizado, está ligado muitas vezes ao estresse e cansaço desenvolvidos no trabalho, remuneração baixa, e sobrecarga no trabalho. Nota-se que o trabalho em excesso, poucos profissionais de plantão, falta de motivação dificultam no oferecimento da humanização do serviço de enfermagem.

A humanização não é um artifício ou técnica, e sim um processo de vivência que permeia todas as atividades desenvolvidas pelos profissionais com a intenção de oferecer o melhor tratamento (GOMES, 1998).

Já de acordo com Carraro (2000) é indiscutível a melhora e cura, quando o paciente e sua família participam do esquema terapêutica. Todo calor humano, conforto, e o 
bem-estar físico e mental. A proximidade entre paciente e família são elementos extremamente importantes para diminuir o sofrimento e a angústia na UTI.

O cuidado humano é algo sentido, exercitado e vivido, ou seja, é algo que não se consegue prescrever, pois não há uma receita para tal. De acordo com Vila e Rossi (2002) a humanização precisa fazer parte da filosofia da enfermagem, pois os recursos humanos são mais significativos que os métodos tecnológicos e materiais.

A sugestão de humanização é, assim, alicerce para se difundir-se a qualidade no atendimento aos pacientes e qualidade de trabalho dos profissionais, ficando evidente que o cuidado e humanização não podem ser desmembrados, pois cuidar é um ato que, além de artifícios técnicos e conhecimento, une atitudes e comportamentos (WALDOW, 2004).

De acordo com Bolela e Jericó (2006), a conceituação de humanização é uma procura continuada do conforto psíquico, físico e espiritual do paciente, dos familiares e da equipe, aclarando assim a seriedade da mesma no decorrer do andamento da internação, mirando tornar eficaz a assistência ao usuário.

A equipe de enfermagem precisa pensar a respeito dos princípios da sua prática profissional, pois a ética profissional abrange motivação, atos, ideais, estimas, princípios e intenções, além de ser um organismo que gere as relações sociais do homem e avaliza a coerência social, pois harmoniza as inclinações tanto do indivíduo como coletivos. Compreende-se então que é imprescindível reconhecer a relevância da humanização; humanizar o cuidado é uma maneira de relacionamento com o próximo, não apenas focalizado nas atividades que Ihe proporcionam a sobrevivência, mas de respeitar os sentimentos do outro, espalhando empenho, ao tocar, escutar ou, falar (BARBOSA e SILVA 2007).

O profissional necessita se identificar como ser humano, atuar de maneira ética, humanizada, perceber o que o outro sofre, se colocar no lugar e ter capacidade de medir e escolher como ele adoraria de ser tratado naquela situação (LEITE e VILA, 2005). 


\section{CONSIDERAÇÕES FINAIS}

Após a confecção do presente estudo, foi possível entender o significado e relevância da humanização no acolhimento dos familiares e pacientes internados em Unidades de Terapia Intensiva.

Para que toda equipe possa atingir os objetivos de humanização, é necessário não somente acolher os pacientes, como também sua família. Analisando todos os obstáculos que a família enfrenta no decorrer da permanência do paciente internado na UTI, nota-se que o profissional de enfermagem se volta a realização de atos de maneira técnica, e muitas vezes esquece de acolher a família dos pacientes.

Perante tudo que foi apresentado na presente pesquisa, é possível concluir que para tomar os cuidados de humanização, não basta somente investir em eficiência técnico cientifica, é necessário também se atentar a valores e princípios que se voltam para a solidariedade.

Os enfermeiros são de suma importância dentro das Unidades de terapia intensiva, pois são profissionais preparados para desenvolver o acolhimento e humanização e também são as pessoas mais próximas dos pacientes, por estarem com eles 24 horas do dia dando toda assistência.

Nota-se, portanto, que o estudo em questão pode servir de base para confecção de outros estudos, bem como servir de conhecimento para os enfermeiros que desejam trabalhar em Unidades de terapia intensiva.

\section{REFERÊNCIAS}

BACKES, D. S. et al.. Sistematização da assistência de enfermagem: percepção dos enfermeiros de um hospital filantrópico. Acta Sci. Health Sci, Maringá, v. 27, n. 1, p. 25-29, 2005. 
BARBOSA, I. A.; SILVA, M. J. P. Cuidado humanizado de Enfermagem: o agir com respeito em um hospital universitário. Revista Bras Enferm 2007 Set-Out; 60(5): 54651

BOLELA, F; JERICÓ, M. C. Unidades de terapia intensiva: considerações da literatura acerca das dificuldades e estratégias para sua humanização. Esc. Anna Nery Rev. Enferm. 2006; 10(2).

BRASIL. Ministério da Saúde. Programa Nacional de Humanização Hospitalar. Brasília. 2002.

CARRARO, T. E. Tecnologia e humanização: da sua união as possibilidades de prevenção de infecções. Florianópolis. Rev. Texto e Contexto Enfermagem, v. 09, n.을 01, p 42-62, 2000

COMASSETTO, I. Vivências dos familiares do paciente internado em unidade de terapia intensiva: um estudo fenomenológico, 2006. Dissertação, Escola de Enfermagem, Universidade Federal do Rio Grande do Norte, Natal

COSTA, S.C.; FIGUEIREDO, M.R.B.; SCHAURICH, D. Humanização em Unidade de Terapia Intensiva adulta (UTIs): compreensão da equipe de enfermagem. Interface - Comunic., Saúde. Educ., v.13, supl.1, p.571-80, 2009.

CREMESP . Conselho Regional de Medicina. Resolução CREMESP № 71, de 08 de novembro de 1995. Diário Oficial do Estado; Poder Executivo, São Paulo, SP, 217, 14 nov. 1995.

CUNHA, N. A. Sistematização da Assistência de Enfermagem no tratamento de feridas crônicas, Olinda, 2006

FERNANDES, H.S., Junior, S.A.P., \& Costa Filho, R. (2010). Qualidade em terapia intensiva. Revista Brasileira de Clínica Médica, 8(1), 37-46.

FREITAS, G.F.; OGUISSO, T. Perfil de profissionais de Enfermagem e ocorrências éticas. Acta Paul Enferm. 2007 
GOMES, A. M. Enfermagem em unidade de terapia intensiva. São Paulo (SP): EPU; 1998.

GRENVIK, A., \& Pinsky, M. R. (2009). Evolution of the intensive care unit as a clinical center and critical care medicine as a discipline. Critical Care Clinics, 25(1), 239-250.

JERONIMO, R., CHEREGATTI, A. Técnicas de UTI. 2. Ed. São Paulo: Editora Rideel, 2011

KNOBEL, E. Terapia intensiva: Enfermagem. Elias Knobel: coautores Claudia Regina Laselva, Denis Faria Moura Júnior. São Paulo: Editora Atheneus, 2006.

LEITE, M. A.; VILA, V.S.C. Dificuldades vivenciadas pela equipe

multiprofissional: unidade de terapia intensiva. Ver. Latinoam. Enf.. p. 145-50. 2005

LIMA, A. A.; Densidade tecnológica e o cuidado humanizado em enfermagem: a realidade de dois serviços de saúde. Salvador, 2013. 105 p. Dissertação (Mestrado em Saúde Coletiva-área de concentração: Avaliação de Tecnologias em Saúde).

MACHADO, D. T. G. O que é a SAE? Qual a sua importância?. 2010. Disponível em: < http://olharesevivenciasdeumaprendiz.blogspot.com.br/2010/07/o-que-e-saequal- importancia.html >. Acesso em: 04 Out. 2019

MARTINS, J.J.; NASCIMENTO, E.R.P. A tecnologia e a organização do trabalho da Enfermagem em UTI. Arq Catarinenses Méd, 2005

MEZZOMO, J.C. Hospital Humanizado. Fortaleza: Premius Editora, 2001. MORAES, L. O.; PENICHE, A. C. G. Assistência de Enfermagem no período de recuperação anestésica: revisão de literatura. Rev Esc Enferm USP, v. 37, n. 4, p. 34-42, 2003. 
NOGUEIRA, L. S., Sousa, R. M. C., Padilha, K. G., Koike, K. M. (2012). Características clínicas e gravidade de pacientes internados em UTls públicas e privadas. Texto contexto - enfermagem, 21(1), 59-67, 2012.

OLIVEIRA, M. E. Mais uma nota para a melodia da humanização. In: OLIVEIRA, M. E.; ZAMPIERI, M. F. M; BRUGGEMANN, O . M. A melodia da humanização: reflexos sobre o cuidado durante o processo do nascimento. Florianópolis. Ed. Cidade Futura, 2001.

OLIVEIRA. Nara E,S. OliVEIRA. L, M, A, C. ALVARENGA. R, L, G. BRASIL. C, V, V. Humanização na teoria e na prática: a construção do agir de uma equipe de enfermeiros. Rev. Eletr. Enf. [Internet]. 2013 abr/jun;15(2):334-43.

PAULI, M. C.; BOUSSO, R. S. Crenças que permeiam a humanização da assistência em unidade de terapia intensiva pediátrica. Rev. Latino-Am. Enferm.,2003, v. 11, n. 3, p. 2806

PICCOLI, M.; MATOS, F. G. O. A. Sistematização da Assistência de Enfermagem Perioperatória In: Seminário Nacional Estado e Políticas Sociais no Brasil. 2003.

SALICIO. Dalva, M, B. GAIVA. M, A, M, G. O significado de humanização da assistência para enfermeiros que atuam em uti. Revista Eletrônica de Enfermagem, v. 08, n. 03, p. 370 - 376, 2006

SILVA, L.. D. Cuidados ao paciente crítico: fundamentos para a Enfermagem. 2. ed. Rio de Janeiro: Cultura Médica, 2003

SILVA, M. J. P. Humanização em UTI: Assistência de Enfermagem ao paciente crítico. São Paulo: Atheneu, 2000

SOUSA, L. N. A.; PADILHA, M. I. C. S. A humanização na UTI: um caminho em construção. Texto \& Contexto Enferm. 2000 mai-ago: 9(2): 324-35.

STEFANELLI, M.C. Comunicação com paciente - teoria e ensino. $2^{\mathrm{a}}$ ed. São Paulo (SP): Robe Editorial, 1993. 
TANNURE, M. C. GONÇALVES, A. M. P. SAE - Sistematização da Assistência de Enfermagem. 1 ed. São Paulo: Guanabara Koogan, 2008. 168

VILA, V. da S. C.; ROSSI, L. A. O significado cultural do cuidado humanizado em unidade de terapia intensiva: "muito falado e pouco vivido". Rev. Latino americana de Enfermagem. v. 10, n.ํ 02, p. 137 - 144, 2002.

WALDOW, V.R. O cuidado na saúde: as relações entre o eu, o outro e o cosmos. Petrópolis: Vozes; 2004

Enviado: Setembro, 2019.

Aprovado: Outubro, 2019. 